\title{
Bandpass Filter with Interdigital Capacitor in Open Loop Resonator for Wimax, RF-MEMS, and PCS Applications
}

\author{
Kangana Saini ${ }^{1}$, Ashok Kumar ${ }^{1 *}$, Kundan Singh Rathore ${ }^{1}$, and Muquaddar Ali ${ }^{2}$ \\ ${ }^{I}$ Department of Electronics and Communication Engineering, Govt. Mahila Engineering College, Ajmer, Rajasthan- 305002 \\ ${ }^{2}$ Department of Electronics and Communication Engineering, MNIT Jaipur, Rajasthan-302017 \\ *kumarashoksaini@gmail.com
}

\begin{abstract}
In this paper, the design of a bandpass filter (BPF) using open-loop resonator (OLR) with interdigital capacitor added in one set of a half-wavelength resonator is presented. The open-loop resonator filter is constructed by placing a half-wavelength microstrip lines to achieve enhanced filter performance. The interdigital capacitors are employed to control the center frequency easily. An open-loop resonator is derived from one and half-wavelength resonator, which is used to enhance bandwidth. It also introduces transmission zeros in the passband. The three coupling methods, such as electric, magnetic, and mixed-couplings, are used to design the filter with desired characteristics. The filter is operating at $1.93 \mathrm{GHz}$ and $2.41 \mathrm{GHz}$ with $3 \mathrm{~dB}$ bandwidth of $8.8 \%$ and $9.5 \%$, insertion loss of $0.6 \mathrm{~dB}$ and $0.5 \mathrm{~dB}$, return loss of passbands $>15$ $\mathrm{dB}$, and two transmission zeros at $1.71 \mathrm{GHz}$ and $2.88 \mathrm{GHz}$ with better sharpness. The simulation performance evaluations of the filter are carried out using Computer Simulation Technology (CST). The proposed filter makes it very desirable for WiMAX and high-performance RF microelectromechanical system (RF-MEMS) tunable filter and PCS applications.
\end{abstract}

Keywords: Bandpass Filter (BPF), OLR, WiMAX, RF-MEMS

\section{Introduction}

$\mathrm{RF}$ filter is the critical component of wireless communication systems. In fast-growing technologies, the multi-band filters are highly desirable. Different approaches to mitigate the challenges associated with the design of a multi-band or dual-band bandpass filters have been proposed [1-8]. A dual-band bandpass filter design using a novel feed scheme which provides enough degrees of freedom to control the center frequency and bandwidth of the two passbands [1]. A compact bandpass filter using a polygonal open-loop resonator provided compactness in the microstrip bandpass filter [2]. However, it does cover large frequency bands [2]. Two novel dual-band bandpass filters with multiple transmission zeros were proposed $\lambda / 4$ stepped-impedance resonators (SIRs) [3].

The stepped impedance parallel lines have been proposed to design BPFs and its various configurations were also investigated [4-6]. Some other resonator depends on Euclidean figures [7-9] and fractal shapes [10] have also been investigated. The inter-digital capacitor approach was used to control the bandwidth of the filter. A high-selectivity planar multi-band bandpass filter with high interference suppression between the bands was presented [15] The proposed filter utilizes two different kinds of resonators, i.e., stub-loaded resonator and open-loop resonator. An open-loop resonator was embedded inside the stub-loaded resonator to achieve compactness of the circuit. A novel microstrip balun bandpass filter (BPF) was designed by using open-loop resonators having interdigital capacitors [16]. The interdigital capacitors were employed to control the center frequency easily. The opposite phase difference between the balanced outputs can be provided according to the suitable coupling topologies based on parallel and anti-parallel coupled lines. By using this method, minimized magnitude imbalances between the balanced ports can also be obtained. In order to achieve two poles inside the passband, two identical resonators were coupled to each other.

In this paper, a dual bandpass filter with the interdigital capacitors and open-loop resonator is presented. It is suitable for WiMAX, RF microelectromechanical system (RFMEMS) based tunable filters, and personal communication services (PCS) applications. The open-loop resonator filter is constructed by placing the half-wavelength microstrip lines implemented by an open-loop shape with a specific coupling structure to achieve desired filter performance. An open-loop resonator utilizes the odd and even mode field configurations which enhances the bandwidth and introduces transmission zeros in the passband. The electric, magnetic, and mixedcoupling methods are used to design the filter with desired characteristics. Two dual-band open-loop resonators with $7.3 \%$ and $12 \%$ bandwidth are utilized, respectively. Further, the interdigital capacitor is also used to increase the bandwidth by changing the length, gap, and width. The coupling coefficient can conveniently be tuned up to the desired value within a wide range of bandwidth. Based on this idea, the filter is implemented operating at $1.93 \mathrm{GHz}$ for RFMEMS, PCS, and WiMAX applications.

\section{Proposed filter design}

The configuration of the proposed filter is shown in Figure 1. It is consisting of using two open-loop resonators and two interdigital capacitors. There are seven different length segments of open-loop resonator those are not connected to each other. The filter is designed on Rogers substrate (Rogers RT 5880) with relative permittivity of 2.2 and a thickness of $0.787 \mathrm{~mm}$. The overall dimension of the filter is $28.3 \mathrm{x}$ $21.7 \mathrm{~mm}^{2}$. This filter has $8.8 \%$ and $9.5 \%$ wider bandwidth with center frequencies $1.93 \mathrm{GHz}$ and $2.41 \mathrm{GHz}$, respectively. The entire simulation is carried out using Computer Simulation Technology (CST). 


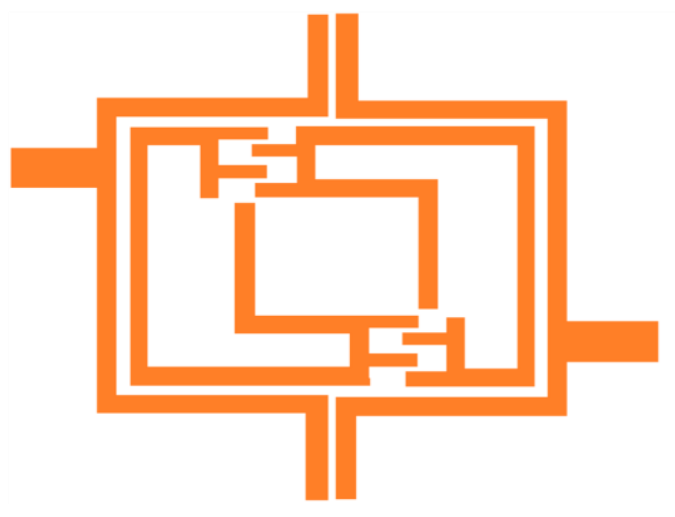

(a)
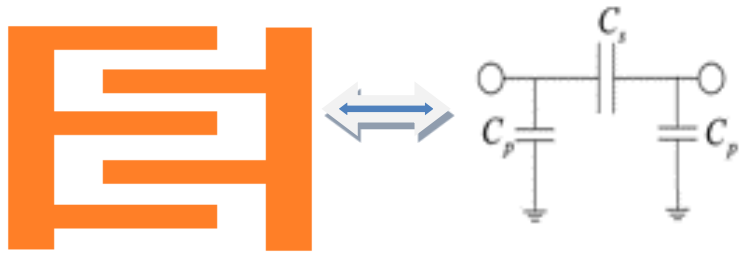

(b)

Fig. 1 (a). Configuration of the proposed bandpass filter, (b). Interdigital capacitor with its equivalent circuit.

\section{Structure development and frequency response}

Initially, open-loop single resonator is studied. Figure 2 shows the structure of open-loop single resonator with its frequency response in Figure 2. It consists of two transmission lines of $50 \Omega$ are connected to the outer openloop resonators, acting as input and output ports. It provides single pass band. To achieve dual pass band, an open-loop resonator with interdigital capacitors are embedded inside the open-loop resonator of Figure 2 as shown in Figure 3 (a). The frequency response of the proposed filter is shown in Figure 3(b). The interdigital capacitors are utilized to realize interstage coupling, which provides increased bandwidth and compactness in microstrip bandpass filter. In order to provide enough degrees of freedom for achieving both wide and narrow upper passband, interdigital capacitors are employed to control the coupling strength within a wide range of frequencies. It can conveniently be tuned by changing the number of fingers, length of the fingers, and the gap between fingers. It is also noted that the coupled lines can be used instead of the interdigital capacitor in case of a narrow upper passband. The overall length (L) of the outer lines can be calculated as:

$$
\mathrm{L}=\mathrm{L}_{1}+2 \mathrm{~L}_{2+} 2 \mathrm{~L}_{3}+\mathrm{d}+\mathrm{W}
$$

Open-circuited coupled lines with the length $\mathrm{L}_{3}$ and gap are employed to realize electrical coupling.

Due to brevity, the variations of a few shape parameters are shown here. The variation of parameters $m_{6}$ and $n_{6}$ are demonstrated in Figures 4 and 5, respectively. It is observed that the desired frequency bands can conveniently be tuned by varying the shape parameters $\mathrm{m}_{6}$ and $\mathrm{n}_{6}$. The optimized shape parameters of the proposed filter are shown in Table 1.

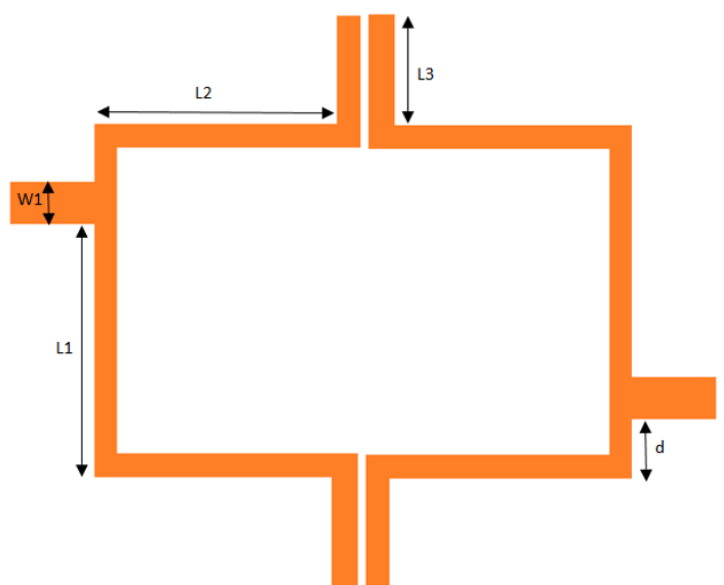

(a)

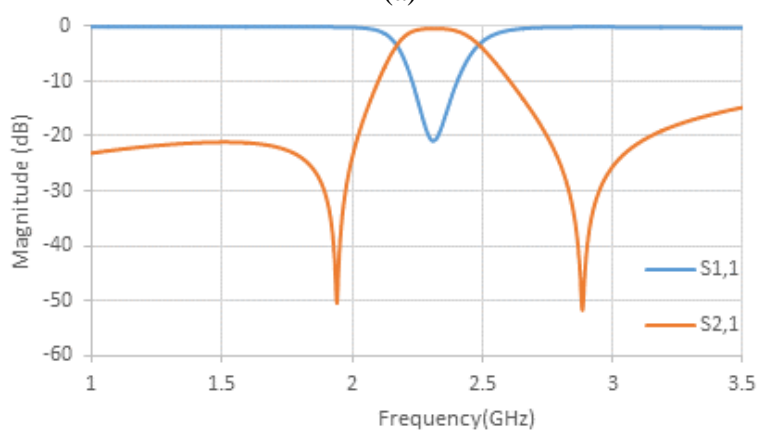

(b)

Fig. 2. Single resonator (a) geometry (b) frequency response

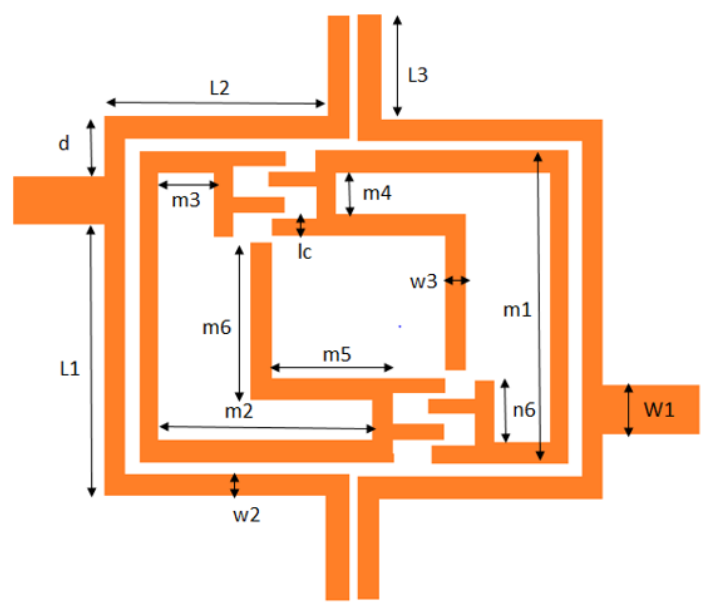

(a)

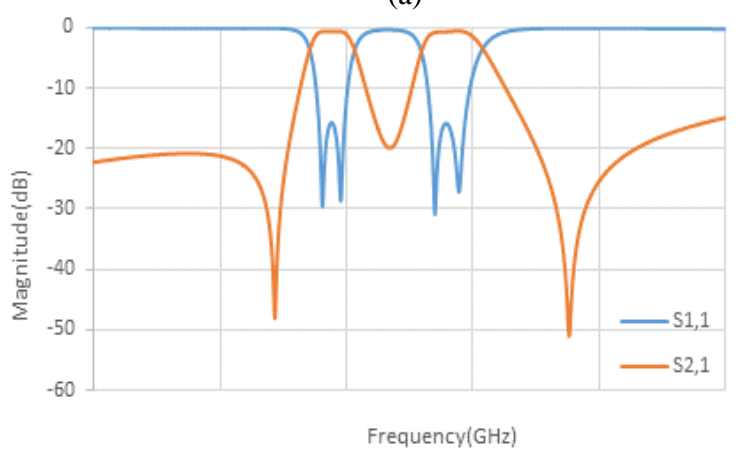

(b)

Fig. 3. Dual-band pass filter (a) geometry (b) frequency response 


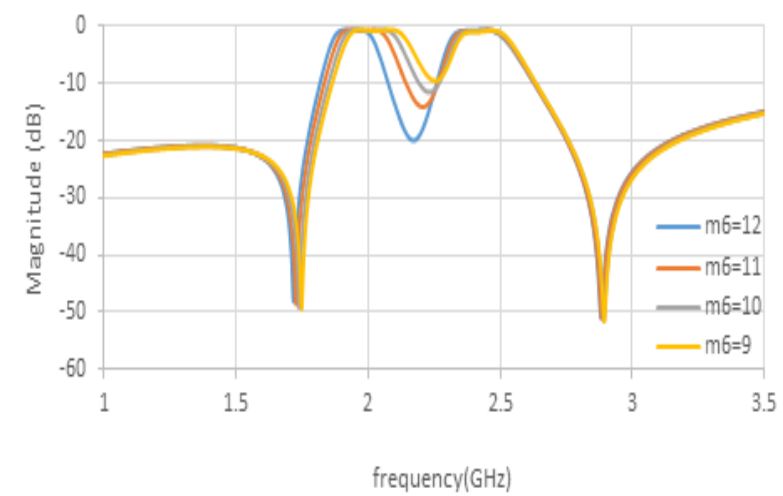

(a)

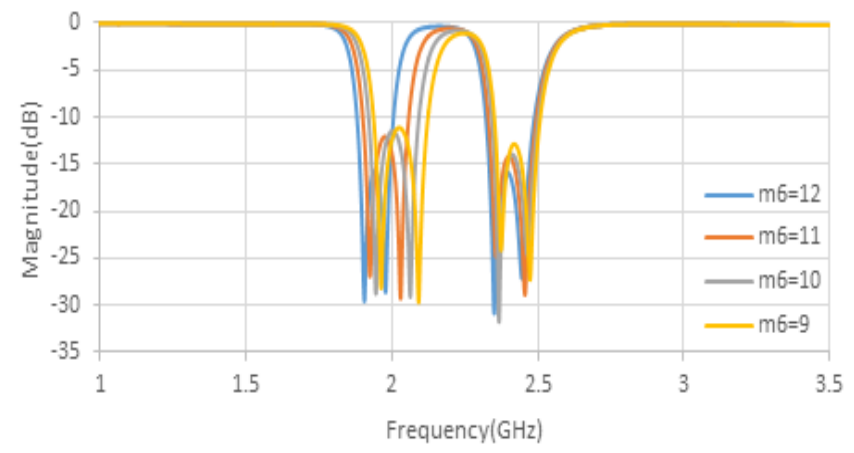

(b)

Fig. 4. Variation of different values of $\mathrm{m}_{6}$ (a) insertion loss (b) reflection coefficient

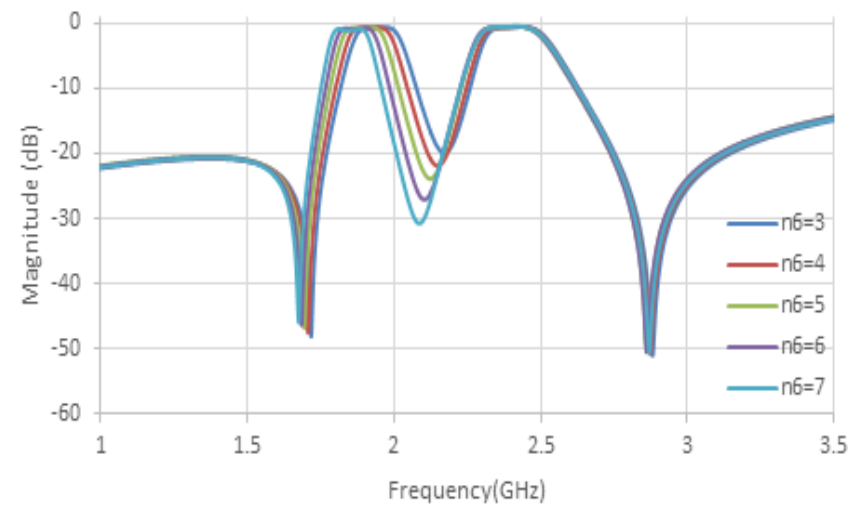

(a)

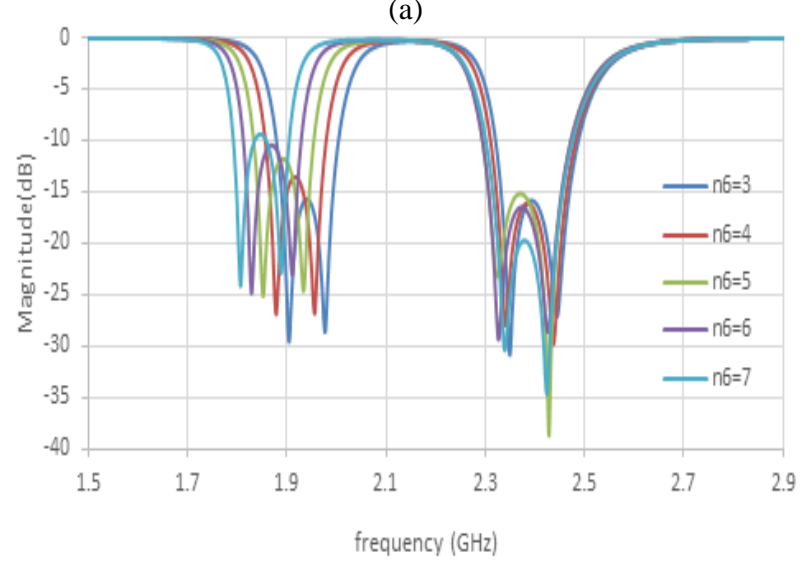

(b)

Fig. 5. Variation of different values of $\mathrm{n}_{6}$ (a) insertion loss (b) reflection coefficient.
Table 1. Optimized shape parameters of the proposed filter. All dimensions are in millimeter.

\begin{tabular}{|c|c|c|c|}
\hline Parameter & L1 & L2 & L3 \\
\hline Value & 12.55 & 10.65 & 4.9 \\
\hline Parameter & W1 & W2 & W3 \\
\hline Value & 2.4 & 0.7 & 0.5 \\
\hline Parameter & $\mathrm{m} 1$ & $\mathrm{~m} 2$ & $\mathrm{~m} 3$ \\
\hline Value & 16.3 & 10.15 & 1.8 \\
\hline Parameter & $\mathrm{m} 4$ & $\mathrm{~m} 5$ & $\mathrm{~m} 6$ \\
\hline Value & 2 & 5.5 & 12 \\
\hline Parameter & $\mathrm{n} 6$ & $\mathrm{~d}$ & $\mathrm{lc}$ \\
\hline Value & 3 & 3.55 & 3.7 \\
\hline
\end{tabular}

\section{Results analysis}

Dual-band bandpass filter is designed in this paper as a approaches with outer resonators and inner resonator (open loop resonators with polygonal form and interdigital capacitor). The overall filter dimensions are $28.3 \times 21.7 \mathrm{~mm}^{2}$ using Rogers substrate (RT 5880) with relative permittivity of 2.2 and thickness of $0.787 \mathrm{~mm}$. The simulated S-parameters results of the proposed optimized filter is shown in Figure 6. It is observed that the first and second frequency bands are observed between $1.85 \mathrm{GHz}$ to $2.02 \mathrm{GHz}$ and $2.30 \mathrm{GHz}$ to $2.53 \mathrm{GHz}$ with center frequencies $1.93 \mathrm{GHz}$ and $2.41 \mathrm{GHz}$, respectively. The $3-\mathrm{dB}$ bandwidth of $8.8 \%$ and $9.5 \%$ with insertion loss $0.6 \mathrm{~dB}$ and $0.5 \mathrm{~dB}$, respectively observed for both passbands with better than $15 \mathrm{~dB}$ returnloss. There are two transmission zeros observed at $1.71 \mathrm{GHz}$ and $2.88 \mathrm{GHz}$ which means that there is a sharp cut before and after the passband.

The proposed filter is compared with the filters available in open literature, which is shown in Table 2.

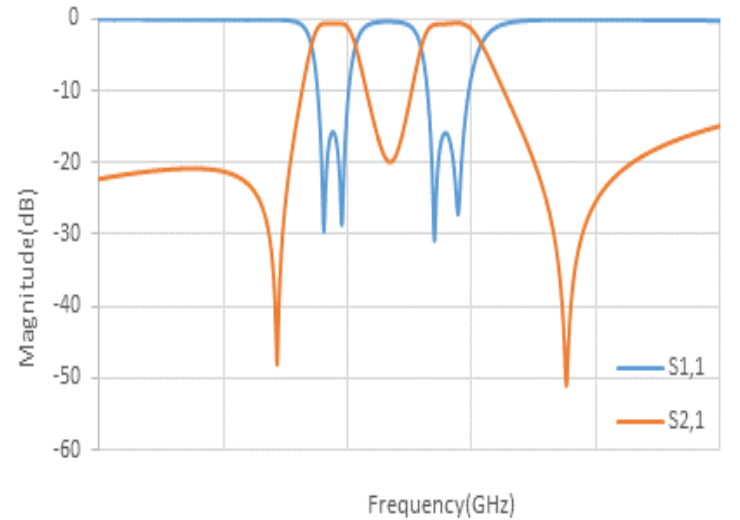

Fig. 6 Simulation results of proposed filter

Table 2 Comparison with available literatures

\begin{tabular}{|l|l|l|l|l|l|l|l|}
\hline Reference & $\begin{array}{l}\text { Passband } \\
(\mathrm{GHz})\end{array}$ & $\begin{array}{l}\text { No. of } \\
\text { bands }\end{array}$ & $\left.\begin{array}{l}-3 \mathrm{~dB} \\
\text { FBW }(\%)\end{array}\right)$ & $\begin{array}{l}\text { Insertion } \\
\text { loss }(\mathrm{dB})\end{array}$ & $\begin{array}{l}\text { Return } \\
\text { loss }(\mathrm{dB})\end{array}$ & $\begin{array}{l}\text { Transmiss- } \\
\text { ion zeros }\end{array}$ & $\begin{array}{l}\text { Filter size } \\
\text { mmx mm }\end{array}$ \\
\hline$[1]$ & $1.84 / 2.45$ & Dual & $4.9 / 3.8$ & $0.8 / 1.1$ & $17 / 16$ & 4 & $28.3 \times 21.7$ \\
\hline$[2]$ & 2.4 & Single & 19.2 & 0.8 & 26 & 2 & $4.3 \times 5.8$ \\
\hline$[3]$ & $1.57 / 3.70$ & Dual & $4.5 / 4$ & $<2.5$ & $>12$ & 4 & $44 \times 50$ \\
\hline$[12]$ & $1.57 / 2.41$ & Dual & $3 / 2$ & $<2$ & $>15$ & 4 & $21.1 \times 14.1$ \\
\hline$[13]$ & $1.58 / 2.40$ & Dual & $5 / 2$ & 1 & $>16$ & 2 & $26 \times 26$ \\
\hline$[14]$ & 9.3 & Single & 9.25 & 1.58 & 17.7 & 3 & \\
\hline This work $1.93 / 2.41$ & Dual & $8.8 / 9.5$ & $0.6 / 0.5$ & $>15$ & 2 & $28.3 \times 21.7$ \\
\hline
\end{tabular}




\section{Conclusion}

Bandpass filter designed using open-loop resonator with an interdigital capacitor added in one set of half-wavelength resonator. The bandwidth of the filter is increased by changing the length, width, and gap of the Interdigital capacitor. The coupling coefficient can conveniently be tuned up at the desired valve within a wide range bandwidth. The dual bandpass filter with the interdigital capacitor in openloop resonator for WiMAX, RF microelectromechanical system (RF-MEMS) tunable filter and personal communication services (PCS)

\section{References}

[1] X. Y. Zhang, J. Shi, J. X. Chen, and Q. Xue, Dual-band bandpass filter design using a novel feed scheme, IEEE Microwave and Wireless Components Letters, vol. 19, pp.350-352, 2009.

[2] A. J. Salim, A. N. Alkhafaji, M. S. Taha, and J. K. Ali, A polygonal open-loop resonator compact bandpass filter for Bluetooth and WLAN applications, IOP Conference Series: Materials Science and Engineering vol. 433, No.1, 2018.

[3] K. Deng, Z. Chen, G. Hu, and W. Feng, Dual-band bandpass filters with multiple transmission zeros using $\lambda / 4$ stepped impedance resonators, International Journal of RF and Microwave Computer-Aided Engineering, 2019;29:c21469, 2018.

[4] A. Worapishe and A.Surakampontom, Stepped impedance coupled resonators for implementation of parallel coupled microstrip filters with spurious band suppression, IEEE Trans. on Microwave Theory and Techniques, vol. 60, pp1540-1548, 2012.

[5] P. Arunvipas, N. Thammawongsa, S. Krissanapong, and P. Arunvipas, Design of compact micro strip steppedimpedance resonator band pass filters, Procedia Engineering, vol.8, pp 30-35, 2011.

[6] J. Shivhare and B. Reddy, Design and development of a single fold hairpin line microstrip bandpass filter at 3250 $\mathrm{MHz}$ for S-Band communication systems, International Journal of Advances in Engineering and Technology, vol. 8, pp 337-346, 2015.

[7] H. Im H and S. Yun, Design of a dual-band bandpass filter using an open-loop resonator, Journal of Electromagnetic Engineering and Science, vol. 17, pp. 197-201, 2017.

[8] T. Rohit, R. Ramesh, S. Abhishek, H. Habiba, and R. Sandhya, Microstrip open loop resonator using dual feed techniques for wireless applications, IOSR Journal of Electronics and Communication Engineering, vol. 11, pp 13-15, 2016.

[9] S. Khani, S. Makki, S. Mohammad, H. Mousavi, M. Danaie, and P. Rezaei, Adjustable compact dual-band microstrip bandpass filter using T-shaped resonators, Microwave and Optical Technology Letters., vol. 59, pp 2970-2975, 2017.

[10] M. Alqaisy, C. Chakrabraty, J. Ali, and A. Alhawari, A miniature fractal-based dual-mode dual-band microstrip bandpass filter design, International Journal of Microwave and Wireless Technologies, vol. 7, pp 127-133, 2015.

[11] L. Zhu, V. Devabhaktuni, C. Wang and M. Yu Adjustable Bandwidth Filter Design Based on Interdigital Capacitors, IEEE Microwave and Wireless Components Letters, vol.18, 2008.

[12] H. W. Liu, Z. C. Zhang, S. Wang, L. Zhu, X. H. Guan, J. S. Lim, and D. Ahn, Compact dual-band bandpass filter using defected microstrip structure for GPS and WLAN applications, Electronics Letter, vol. 46, pp.1444-1445, 2010.
[13] H.-W. Liu, Y.-F. Lv and W. Zheng, Compact dual-band bandpass filter using trisection hairpin resonator for GPS and WLAN applications, Electronics Letter, vol. 45, pp. 360-362, 2009.

[14] N. D. Salif, Z. Ting, B. Jingfu, and B. Denis, Compact microstrip bandpass filter using dual closed-loop stepped impedance resonator, International Journal of Microwave and Wireless Technologies, vol.10, pp. 405-411, 2018.

[15] J. Parimala, H. U. Habiba, and. S. Pachiyappan, Analysis of stub loaded embedded with open loop resonator for multiband band pass filter, International Journal of Engineering Trends and Technology, vol. 7, 2014.

[16] A. K. Gorur, A novel compact microstrip balun bandpass filter design using interdigital capacitor loaded open loop resonators, Progress In Electromagnetics Research Letters, vol. 76, pp. 47-53, 2018.

\section{Biography of the authors}

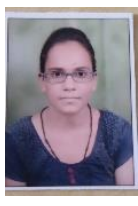

Kangana Saini received the B.Tech. degree in Electronics and Communication Engineering from the Institute of Engineering and Technology, Alwar under Rajasthan Technical University, Kota, India in 2016 and pursuing M.Tech. degree from Govt. Mahila Engineering College, Ajmer, India. His research interests are related to wireless communication, $\mathrm{RF} /$ microwave filters and ultra wideband circuits.

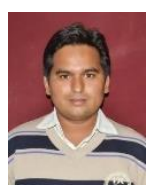

Ashok Kumar received a Ph.D. in Electronics and Communication Engineering from Rajasthan Technical University Kota (2019). He had completed his M. Tech. in Communication Stream from Malaviya National Institute of Technology Jaipur (2011) and B.E. in Electronics and Communication Engineering from University of Rajasthan, Jaipur (2008). Presently, he is working as Assistant Professor in the Electronics and Communication Engineering Department at Government Mahila Engineering College, Ajmer. He has organized various International Conferences as Organising Secretary/Member and many Workshops as Coordinator. He is an active member of IEEE including AP-S and MTT-S and IETE (India) professional societies. He is the author/coauthor of more than 45 research papers published in SCI/Scopus Indexed Journals and Conferences. His current research interest includes design and applications of microwave planar antennas, circularly polarized antennas, reconfigurable antennas, UWB antennas, VANETs etc.

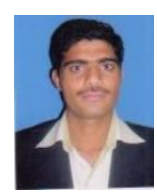

Kundan Singh Rathore received a B.E. degree from Rajasthan University Jaipur, India 2007, and M. Tech. degree from the MNNIT Allahabad, India 2013. He is currently Assistant Professor in Dept. of Electronics and Communication Engineering, Govt. Women Engineering College Ajmer, India. His reseach interest includes Antenna, Wireless communications.

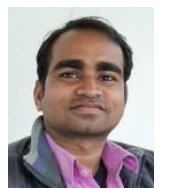

Muquaddar Ali received the B.Tech. degree in Electronics and Communication Engineering from MLVTEC, Bhilwara, under Rajasthan Technical University Kota, Kota, India, in 2011, and M.Tech. degree from the Indian Institute of Technology Roorkee, India, in 2013. He is currently pursuing Ph.D. degree from MNIT Jaipur, India. His research interests include microwave devices, substrate integrated waveguides, slot antennas, microstrip antennas, and beam-forming networks. 